\title{
AN ASSOCIATION BETWEEN HELICOBACTER PYLORI INFECTION AND DYSMETABOLIC SYNDROME IN ADULT EGYPTIAN POPULATION
}

\author{
By
}

\section{${ }^{1}$ Mohammed Yehia Mohammed Awad-Allah, ${ }^{1}$ Abdella Hussien El-Sadek, ${ }^{2}$ Tarek Moustafa Emran and ${ }^{1}$ Saad El-Deen Mohamed El-Shreef}

${ }^{1}$ Department of Internal Medicine, Faculty of Medicine, Al-Azhar Faculty of Medicine (Cairo)

${ }^{2}$ Department of Clinical Pathology, Faculty of Medicine, Al-Azhar Faculty of Medicine

(Damietta)

E-mail: mohammedyehiamohammed1989@gmail.com

\begin{abstract}
Background: Helicobacter pylori (H. pylori) infection is considered to be one of the most popular infections worldwide, affecting more than $50 \%$ of the world's population, principally in the developing countries.

Objective: To determine the possible association between Helicobacter pylori infection and dysmetabolic syndrome in adult Egyptian population, principally cardio-metabolic components. Patients and Methods: Adult patients aged more than 18 years and presented with dysmetabolic syndrome or being metabolically healthy obese were enrolled in the study. All participants were subjected to meticulous history assessment and clinical evaluation.

Results: An overall 60 patients who fulfilled the inclusion criteria were enrolled in the present study. Of them, 30 patients had metabolic syndrome, whereas the remaining 30 patients were metabolically healthy obese. There was a statistically significant difference between both groups regarding the levels of systolic and diastolic blood pressure, lipid profile, and glycemic status. There was an equal proportion of patients had positive Helicobacter Pylori infection among patients with metabolic syndrome and metabolically healthy obese patients. Furthermore, among patients with metabolic syndrome, correlation analysis revealed that; BMI showed a statistically significant positive correlation with Helicobacter Pylori infection.

Conclusion: Helicobacter Pylori infection was highly prevalent infection in patients with metabolic syndrome. Metabolic syndrome patients with Helicobacter Pylori infection have higher blood glucose levels together with disturbed lipid profile. Being positively correlated with H. Pylori infection, patients with high BMI should be laboratory evaluated to role out the presence of Helicobacter Pylori infection.
\end{abstract}

Keywords: H. Pylori infection, metabolic syndrome.

\section{INTRODUCTION}

Helicobacter pylori (H. pylori) infection is considered to be one of the most popular infections worldwide, affecting more than $50 \%$ of the world's population, principally in the developing countries. It may cause chronic gastritis, peptic ulcers and gastric cancer (McColl, 2010 and Lee et al., 2013). A link has been determined between H.pylori infection and various extra-gastric conditions such as DM and non-alcoholic fatty liver (Zhou et al., 2013 and Franceschi et al., 2014). The mechanisms responsible for these associations are 
believed to involve modulation of blood glucose, lipoproteins and inflammatory markers (Upala et al., 2017).

A large number of studies have reported association between H.pylori and other hormones such as insulin, glucagon like peptide- 1 and leptin, some of which are involved in glucose metabolism directly or indirectly. These studies revealed the pathophysiological evidence for association between H.pylori infection and DM risk (Franceschi et al., 2019).

Apart from other gastrointestinal infections, $H$. pylori infection has significant extra-gastrointestinal consequences. It is associated with an atherogenic lipid pro- file and cardiovascular risk via the increases in inflammatory processes in infected individuals (Rabelo-Gonçalves et al., 2015).

The same pathogenesis is found in metabolic syndrome, which is predisposed by pro- inflammatory factors and a hypercoagulability state. Some studies have also demonstrated improvements in clinical markers of metabolic syndrome and systemic inflammation after $\mathrm{H}$. pylori eradication therapy, suggesting that $\mathrm{H}$. pylori infection plays a causative role in this disease. However, many studies have failed to identify associations between $\mathrm{H}$. pylori infection and these extragastrointestinal pathologies (Kim et al., 2017). The association between H. pylori infection and metabolic syndrome was established in many studies (Chen et al., 2015 and Vafaeimanesh et al., 2016).

This study was designed to determine a possible association between Helicobacter pylori infection and dysmetabolic syndrome in adult Egyptian population, and to evaluate the relationship between Helicobacter pylori infection and cardiometabolic components of dysmetabolic syndrome including insulin resistance (HOMA-IR), abdominal obesity, hypertension, impaired glucose homeostasis, and dyslipidemia.

\section{PATIENTS AND METHODS}

This was a prospective case-control study which was performed at Internal Medicine Departments, Al-Azhar University Hospitals (Bab Al-sharia and New Damietta University Hospital) from October 2018 and March 2019.

The current study was carried out based on the recommendations of the ethical committee, Faculty of Medicine, Al-Azhar University, Cairo, Egypt. All clinical steps were illustrated obviously to the all participants prior to study processing. Possible adverse events were demonstrated, and informed consents were obtained.

Adult patients aged more than 18 years and presented with dysmetabolic syndrome based on metabolic syndrome criteria proposed by IDF were enrolled in the case group. Metabolically healthy obese patients were clinically diagnosed (based on $\mathrm{BMI} \geq 30 \mathrm{Kg} / \mathrm{M} 2$ ) without any cardio-metabolic abnormality of metabolic syndrome.

\section{Exclusion Criteria:}

Patients with type I diabetes mellitus, those already on steroid therapy or immunosuppressive drugs or H.pylori eradication therapy, patients with current cigarrete smoking or alcohol consumption and those with active infection on antibiotic therapy or use of non-steroidal 
anti-inflammatory drugs, patients with collagen diseases or inflammatory bowel diseases as ulcerative colitis or crohn's disease, and patients with renal failure, heart failure, liver failure, pregnant women or anemic patients.

All patients were subjected to meticulous history taking with especial emphasis on age, history of diabetes mellitus, hypertension, upper gastrointestinal symptoms, symptoms suggesting of liver impairment, renal impairment or heart failure and chronic inflammatory diseases, history of cigarettes smoking, alcohol consumption, abdominal surgery and current medication. Furthermore, all participants were subjected to the appropriate clinical assessment including assessing blood pressure, weight, waist circumference, full respiratory, cardiac, and neurological examinations, and BMI was calculated.

Patients were subjected to routine investigations such as renal and liver functions, glycemic status, and lipid profile. Diagnosis of H.Pylori infection was established based on $\mathrm{H}$. pylori antigen in human feces samples.

Statistical analysis was performed using SPSS software version 23 for Windows (SPSS Inc., Chicago, IL, USA), and MedCalc software version 14.8 (MedCalc Software, Mariakerke, Belgium). Continuous normally distributed data were reported in the form of mean, and standard deviation (SD), and its groups were compared using student $\mathrm{t}-$ test. On the contrary, continuous nonnormally distributed data were reported using median and range and its related groups were compared using the MannWhitney-U Test. Categorical variables were expressed using the number and percentage and its particular groups were compared using Pearson's chi-square test. Furthermore, correlation analysis was conducted using Spearman's rank correlation coefficient. The significance was established when $\mathrm{P} \leq 0.05$.

\section{RESULTS}

An overall 60 patients who fulfilled the inclusion criteria were enrolled in the present study. Of them, 30 patients had metabolic syndrome, whereas the remaining 30 patients were metabolically healthy obese. There was no statistically significant difference between metabolic syndrome patients and metabolically healthy obese patients regarding the age with a mean of $50.66 \pm 8.42$ and $48.26 \pm 11.94$ years, respectively $(\mathrm{p}=0.372)$. There were $19(63.3 \%)$ and 17 $(56.6 \%)$ males among metabolic syndrome and metabolically healthy groups, respectively $(\mathrm{p}=0.598)$ (Table 1).
Regarding the anthropometric measurements, there was no statistically significant difference between patients with metabolic syndrome and metabolically healthy patients regarding the weight $(p=0.4)$ with a mean of $132.1 \pm 15.98$ and $129.06 \pm 11.32$, respectively. Similar to that, there was no statistically significant difference between both groups regarding the height $(p=0.36)$ with a mean of $1.71 \pm 0.093$ among the metabolic syndrome group, and a mean of $1.68 \pm 0.117$ among the metabolically healthy obese group. Subsequently, there was no statistically significant difference 
between both groups regarding BMI $(\mathrm{p}=0.701)$, and weight circumference $(\mathrm{p}=0.762)$ (Table 1).

There was a statistically significant difference between both groups regarding the levels of SBP with a mean of $152.16 \pm 10.47$ among patients with metabolic syndrome, and a mean of $116.66 \pm 4.79$ among the metabolically healthy group $(\mathrm{p}<0.001)$. In this respect, patients with metabolic syndrome had a statistically significant higher levels of DBP (97.16 \pm 5.82$),$ in contrast to metabolically healthy obese patients (75.33 \pm 4.90 - $\mathrm{p}<0.001)$ (Table 1).

There was a statistically significant difference between metabolic syndrome and metabolically healthy patients regarding the levels of FBG with a mean of $174.06 \pm 15.27$ and 90.03 \pm 7.98 , respectively $(p<0.001)$. Similar to that, the mean levels of $\mathrm{HBA} 1 \mathrm{C} \%$ were significantly high among patients with metabolic syndrome $(7.54 \pm 0.9)$, in comparison to metabolically healthy obese patients $(4.67 \pm 0.44) \quad(p<0.001)$. Besides that, HOMA IR levels were significantly high $(\mathrm{p}<0.001)$ among patients with metabolic syndrome, $12.45 \quad$ (8-89), relative to metabolically healthy obese patients, 1.65 (0.8-2.70) (Table 1).

As for the lipid profile, the mean level of total cholesterol was significantly high $(\mathrm{p}<0.001)$ among patients with metabolic syndrome (262.3 \pm 29.9$)$, in contrast to metabolically healthy obese patients (220.16 \pm 26.9$)$. In this concern, there was a statistically significant difference $(p<0.001)$ between both groups regarding the mean levels of triglyceride with a mean of $200.96 \pm 29.88$ and $134.23 \pm 10.46$ among patients with metabolic syndrome and metabolically healthy groups, respectively. Additionally, the mean levels of HDL-C (27.15 \pm 4.38$)$ and LDL-C (127.96 \pm 25.56$)$ were significantly high among patients with metabolic syndrome, in contrast to metabolically healthy obese patients ( $\mathrm{p}<0.001)$ (Table 1). 
Table (1): Patients demographic characteristics

\begin{tabular}{|c|c|c|c|}
\hline $\begin{array}{l}\text { Groups } \\
\text { Variables }\end{array}$ & $\begin{array}{l}\text { Metabolic syndrome } \\
\text { Group N=30 }\end{array}$ & $\begin{array}{l}\text { Metabolically healthy } \\
\text { group } N=30\end{array}$ & P-Value \\
\hline Age(years) & $50.66 \pm 8.42$ & $48.26 \pm 11.94$ & 0.372 \\
\hline \multicolumn{4}{|l|}{ Sex } \\
\hline Male & $19(63.3 \%)$ & $17(56.6 \%)$ & \multirow{2}{*}{0.598} \\
\hline Female & $11(36.6 \%)$ & $13(43.3 \%)$ & \\
\hline Weight(kg) & $132.1 \pm 15.98$ & $129.06 \pm 11.32$ & 0.4 \\
\hline Height(m) & $1.71 \pm 0.093$ & $1.68 \pm 0.117$ & 0.36 \\
\hline BMI (Kg/m $\left.\mathbf{m}^{2}\right)$ & $45.13 \pm 5.28$ & $45.66 \pm 5.42$ & 0.701 \\
\hline WC (cm) & $138.43 \pm 12.67$ & $139.2 \pm 5.48$ & 0.762 \\
\hline SBP(mmHg) & $152.16 \pm 10.47$ & $116.66 \pm 4.79$ & $<0.001$ \\
\hline DBP(mmHg) & $97.16 \pm 5.82$ & $75.33 \pm 4.90$ & $<0.001$ \\
\hline FBS(mg/dl) & $174.06 \pm 15.27$ & $90.03 \pm 7.98$ & $<0.001$ \\
\hline 2HPPBG(mg/dl) & $253.6 \pm 31.76$ & $129.8 \pm 6.95$ & $<0.001$ \\
\hline HBA1C(\%) & $7.54 \pm 0.9$ & $4.67 \pm 0.44$ & $<0.001$ \\
\hline $\begin{array}{l}\text { Fasting Insulin } \\
(\mathrm{mIU} / \mathrm{ml})\end{array}$ & $48.26 \pm 45.6$ & $7.64 \pm 2.23$ & $<0.001$ \\
\hline HOMA IR & $12.45(8-89)$ & $1.65(0.8-2.70)$ & $<0.001$ \\
\hline TC (mg/dl) & $262.3 \pm 29.9$ & $220.16 \pm 26.9$ & $<0.001$ \\
\hline TG (mg/dl) & $200.96 \pm 29.88$ & $134.23 \pm 10.46$ & $<0.001$ \\
\hline HDL-C (mg/dl) & $27.15 \pm 4.38$ & $48.2 \pm 5.46$ & $<0.001$ \\
\hline LDL-C (mg/dl) & $127.96 \pm 25.56$ & $73.96 \pm 8.77$ & $<0.001$ \\
\hline \multicolumn{4}{|c|}{$\begin{array}{l}\text { Abbreviations; } \mathrm{BMI}=\text { Body mass index, WC=Weight circumference, } \mathrm{SBP}=\text { Systolic } \\
\text { Blood pressure, DBP= Diastolic Blood Pressure, FBS }=\text { Fasting blood sugar, } \\
\text { 2HPPBG }=\text { two hours post prandial blood glucose, HOMA IR= Homeostatic Model } \\
\text { Assessment of Insulin Resistance, TC }=\text { Total cholesterol, TG= Triglyceride, HDL-C }= \\
\text { High Density Lipoprotein Cholesterol, LDL-C=Low Density Lipoprotein Cholesterol. } \\
\text { Data were represented in the form of median and range. }\end{array}$} \\
\hline
\end{tabular}

Out of the included patients, 34 (56.6\%) patients had positive H. Pylori infection. Apart from this, an equal proportion of patients (17) had positive $\mathrm{H}$. Pylori infection among patients with metabolic syndrome and metabolically healthy obese patients.

Among patients with metabolic syndrome, correlation analysis revealed that; BMI showed a statistically significant positive correlation with $\mathrm{H}$. Pylori infection $(\mathrm{r}=0.37, \mathrm{p}=0.044)$. On the contrary, there was no statistically significant correlation between patients age $(\mathrm{r}=0.163, \mathrm{p}=0.38)$, sex $\quad(\mathrm{r}=-0.032$, $\mathrm{p}=0.86)$, weight $(\mathrm{r}=0.233, \mathrm{p}=0.21), \mathrm{WC}$ $(\mathrm{r}=0.276, \mathrm{p}=0.13), \mathrm{SBP}(\mathrm{r}=-0.15, \mathrm{p}=0.41)$ and H. Pylori infection. Similar to that, there was no statistically significant correlation between the levels of FBS $(\mathrm{r}=0.046, \mathrm{p}=0.8), \quad 2 \mathrm{HPPBG} \quad(\mathrm{r}=0.058$, $\mathrm{p}=0.76)$, HBA1C $\% \quad(\mathrm{r}=-0.164, \mathrm{p}=0.38)$, HOMA IR $(\mathrm{r}=-0.128, \mathrm{p}=0.49)$, and positive H. Pylori infection. Among patients with metabolic syndrome, there was no statistically significant correlation between the levels of TC $(r=0.136$, $\mathrm{p}=0.47)$, TG ( $\mathrm{r}=0.062, \mathrm{p}=0.74)$, HDL-C (0.089, $\mathrm{p}=0.36)$, and positive H. Pylori infection (Table 2). 
Table (2): Correlation between demographic and anthropometric measurements, and positive $H$. Pylori infection among patients with metabolic syndrome $(\mathbf{n}=\mathbf{3 0})$

\begin{tabular}{|c|c|c|}
\hline Variables & Correlation Coefficient & P-Value \\
\hline Age & 0.163 & 0.38 \\
\hline Sex & -0.032 & 0.86 \\
\hline Weight(kg) & 0.233 & 0.21 \\
\hline Height(m) & -0.135 & 0.47 \\
\hline BMI $\left(\mathrm{Kg} / \mathrm{m}^{2}\right)$ & 0.37 & 0.044 \\
\hline WC (cm) & 0.276 & 0.13 \\
\hline SBP(mmHg) & -0.15 & 0.41 \\
\hline DBP(mmHg) & -0.21 & 0.25 \\
\hline FBS(mg/dl) & 0.046 & 0.8 \\
\hline 2HPPBG(mg/dl) & 0.058 & 0.76 \\
\hline HBA1C $(\%)$ & -0.164 & 0.38 \\
\hline $\begin{array}{l}\text { Fasting Insulin } \\
(\mathrm{mIU} / \mathrm{ml})\end{array}$ & -0.19 & 0.31 \\
\hline HOMA IR & -0.128 & 0.49 \\
\hline TC (mg/dl) & 0.136 & 0.47 \\
\hline TG (mg/dl) & 0.062 & 0.74 \\
\hline HDL-C(mg/dl) & 0.0897 & 0.36 \\
\hline LDL-C(mg/dl) & -0.02 & 0.88 \\
\hline \multicolumn{3}{|c|}{$\begin{array}{l}\text { Abbreviations; BMI }=\text { Body mass index, } \mathrm{WC}=\text { weight } \text { Circumference, SBP= } \\
\text { Systolic Blood pressure, DBP= Diastolic Blood Pressure, FBS= Fasting blood } \\
\text { sugar, 2HPPBG }=\text { two hours post prandial blood glucose, HOMA IR= Homeostatic } \\
\text { Model Assessment of Insulin Resistance, TC }=\text { Total cholesterol, TG= Triglyceride, } \\
\text { HDL-C= High Density Lipoprotein Cholesterol, LDL-C = Low Density Lipoprotein } \\
\text { Cholesterol. }\end{array}$} \\
\hline
\end{tabular}

\section{DISCUSSION}

Helicobacter pylori is still the most prevalent infection of the world. It is a gram-negative, spiral-shaped pathogenic bacterium that specifically colonizes in the gastric epithelium. The infection induces an acute polymorph nuclear infiltration in the gastric mucosa and which is gradually replaced by an immunologically mediated, chronic, predominantly mononuclear cellular infiltrate. Also, local production and systemic diffusion of pro-inflammatory cytokines may exert their effects in remote tissues and organic systems and result in extra gastric manifestations. Thereafter, there were an alarming concern in testing the association between $H$. Pylori infection and metabolic syndrome (Buzás, 2014 and Ražuka- Ebela et al., 2018).

In this study, there was no statistically significant difference between metabolic syndrome patients and metabolically healthy obese patients regarding the age, sex. In this concern, there was no statistically significant difference between patients with metabolic syndrome and metabolically healthy patients regarding the anthropometric measurements. On the other hand, healthy obese participants showed lower levels of blood pressure, glycemic status, and lipids despite having the same proportion of $\mathrm{H}$. Pylori infection metabolically obese patients. 
These findings were in agreement with Hinnouho et al. (2013) who reported that, depending on the definition used for metabolic status, a total of $10-40 \%$ of obese individuals have the metabolic healthy obese phenotype with a good metabolic profile characterized by high levels of insulin sensitivity, low prevalence of hypertension, and a favorable fasting glucose, lipid, and inflammation profile . In the current study, we assessed the $\mathrm{H}$. Pylori infection through detection of the bacterial antigen in the stool of all participants. Prevalence of helicobacter pylori infection in the metabolic syndrome group was similar when compared to the metabolically healthy obese patients.

HP infection plays a role in some endocrine disorders (Talebi-Taher et al., 2012). Two previous studies denoted that the prevalence of HP infection was significantly higher in diabetic patients (Vafaeimanesh et al., 2014 and Vafaeimanesh et al., 2016). Studies were included in a meta- analysis studied the association between Metabolic syndrome and Helicobacter pylori infection, including five cross- sectional studies (Naja et al., 2012, Shin et al., 2012 and Chen et al., 2015), and one cohort study (Chen et al., 2015). There was a statistically significant association between $\mathrm{H}$. pylori infection and metabolic syndrome. Other studies have also found that Helicobacter pylori infection is not only associated with Metabolic syndrome but also with diabetes and insulin resistance (Shin et al., 2012, Vafaeimanesh et al., 2014 and Chen et al., 2015). The possible pathophysiology that underlies these associations could be explained in the same manner as in relation to atherosclerosis, cardiovascular and cerebrovascular diseases by several potential mechanisms including pro- inflammatory cytokines, oxidative stress, immunological cross reactivity, hyper coagulation, endothelial dysfunction, platelet aggregation, increased blood pressure and insulin resistance (Tang et al., 2019 and Guillermo et al., 2020).

Based on the results of the correlation analysis, BMI showed a statistically significant positive correlation with $\mathrm{H}$. Pylori infection. This finding was compliant with Yang and Xuan study (2016). They reported that elderly patients with $\mathrm{H}$. pylori infection had a higher BMI a higher incidence of metabolic syndrome. Furthermore, certain studies suggested that $\mathrm{H}$. pylori infection has a causative association with metabolic syndrome through pathophysiological analysis (Ando et al., 2013). Conversely, on the contrary, there was no statistically significant correlation between patient's age, sex, weight, WC, SBP and Helicobacter pylori infection. In this respect, Naja et al. (2012) reported no suggested association of $\mathrm{H}$. pylori infection with IR or MetS in Lebanese adults. Similarly, Tamura et al (2015) identified no association between $\mathrm{H}$. pylori infection and diabetes in a Japanese population. On the other hand, several studies reported a significant correlation between insulin resistance and fasting blood glaucous (Upala et al., 2016 and Yang \& Xuan, 2016).

In addition to national and regional factors, these inconsistent results may be due to the different screening methods for H. pylori infection among different 
studies. H. pylori infection is diagnosed on the basis of clinical and laboratory findings, as well as microbiological and histopathological examinations following endoscopy.

Despite the obtained evidence in the current study, there were some limitations. In particular, the lack of randomization, the small sample size, and the short-term follow up period might restrict the evidence of this study. To account for these limitations, further studies with a randomized design and a considerable number of patients are necessary to tackle the limitations of the present study.

\section{CONCLUSION}

Helicobacter Pylori infection is highly prevalent infection in patients with metabolic syndrome. Metabolic syndrome patients with helicobacter pylori infection are speculated to have higher blood glucose levels together with disturbed lipid profile. Being positively correlated with H. Pylori infection, patients with high BMI should be laboratory evaluated to rule out the presence of $\mathrm{H}$. pylori infection.

\section{REFERENCES}

1. Ando, T., Ishikawa, T., Takagi, T., Imamoto, E., Kishimoto, E., Okajima, A. and Kokura, S. (2013): Impact of $\mathrm{H}$ elicobacter pylori Eradication on Circulating Adiponectin in Humans. Helicobacter, 18(2): 158-164.

2. Buzás, G. M. (2014): Metabolic consequences of Helicobacter pylori infection and eradication. World Journal of Gastroenterology: WJG, 20(18): 5226-5234.
3. Chen, T. P., Hung, H. F., Chen, M. K., Lai, H. H., Hsu, W. F., Huang, K. C. and Yang, K. C. (2015): Helicobacter pylori infection is positively associated with metabolic syndrome in Taiwanese adults: a cross sectional study. Helicobacter, 20(3):184-191.

4. Franceschi, F., Covino, M. and Roubaud Baudron, C. (2019): Helicobacter pylori and extragastric diseases. Helicobacter, 24: e (1) 2636 .

5. Franceschi, F., Zuccalà, G., Roccarina, D. and Gasbarrini, A. (2014): Clinical effects of Helicobacter pylori outside the stomach. Nature Reviews Gastroenterology \& Hepatology, 11(4): 234-242.

6. Guillermo, A., Eduardo, C. and Edgar, E. (2020): Association between Glycosylated Hemoglobin (HbA1c) and Metabolic Syndrome with Helicobacter Pylori Infection in Guatemala. Metabolism-Clinical and Experimental, 82(1):87-104.

7. Hinnouho, G.-M., Czernichow, S., Dugravot, A., Batty, G. D., Kivimaki, M. and Singh-Manoux, A. (2013): Metabolically healthy obesity and risk of mortality: does the definition of metabolic health matter? Diabetes care, 36 (8): 2294-2300.

8. Kim, T. J., Sinn, D. H., Min, Y. W., Son, H. J., Kim, J. J., Chang, Y. and Ryu, S. (2017): A cohort study on Helicobacter pylori infection associated with nonalcoholic fatty liver disease. Journal of Gastroenterology, 52(11): 1201-1210. 
9. Lee, Y.-C., Chen, T. H.-H., Chiu, H.-M., Shun, C.-T., Chiang, H., Liu, T.-Y. and Lin, J.-T. (2013): The benefit of mass eradication of Helicobacter pylori infection: a community-based study of gastric cancer prevention. Gut, 62(5): 676682.

10. McColl, K. E. (2010): Helicobacter pylori infection. NEW ENGLAND JOURNAL OF medicine, 362 (17): 1597-1604.

11. Naja, F., Nasreddine, L., Hwalla, N., Moghames, P., Shoaib, H., Fatfat, M. and Gali Muhtasib, $\mathbf{H}$. (2012): Association of $H$. pylori Infection with Insulin Resistance and Metabolic Syndrome among L ebanese Adults. Helicobacter, 17(6): 444-451.

12. Rabelo-Gonçalves, E. M., Roesler, B. M. and Zeitune, J. M. (2015): Extragastric manifestations of Helicobacter pylori infection: Possible role of bacterium in liver and pancreas diseases. World journal of hepatology, 7(30): 2968-2979.

13. Ražuka- Ebela, D., Giupponi, B. and Franceschi, F. (2018): Helicobacter pylori and extragastric diseases. Helicobacter, 23: e (1)25-43.

14. Shin, D. W., Kwon, H. T., Kang, J. M., Park, J. H., Choi, H. C., Park, M. S. and Cho, B. (2012): Association between metabolic syndrome and Helicobacter pylori infection diagnosed by histologic status and serological status. Journal of clinical gastroenterology, 46(10): 840-845.
15. Talebi-Taher, M., Mashayekhi, M., Hashemi, M. H. and Bahrani, V. (2012): Helicobacter pylori in diabetic and non-diabetic patients with dyspepsia. Acta Medica Iranica, 315-318.

16. Tamura, T., Morita, E., Kawai, S., Sasakabe, T., Sugimoto, Y., Fukuda, N. and Hishida, A. (2015): No association between Helicobacter pylori infection and diabetes mellitus among a general Japanese population: a cross-sectional study. Springer plus, 4(1):602-633.

17. Tang, D. M., Chascsa, D. M., Chou, J. Y., Ho, N., Auh, S., Wank, S. A. and Kumar, S. (2019): Helicobacter pylori infection is strongly associated with metabolic syndrome, and weakly associated with non- alcoholic fatty liver disease, in a US Hispanic population. Gastro Hep; 1(6): 325331.

18. Upala, S., Jaruvongvanich, V., Riangwiwat, T., Jaruvongvanich, $\mathrm{S}$. and Sanguankeo, A. (2016): Association between Helicobacter pylori infection and metabolic syndrome: a systematic review and meta- analysis. Journal of Digestive Diseases, 17(7): 433-440.

19. Upala, S., Sanguankeo, A., Saleem, S. A. and Jaruvongvanich, V. (2017): Effects of Helicobacter pylori eradication on insulin resistance and metabolic parameters: a systematic review and meta-analysis. European Journal of Gastroenterology \& Hepatology, 29(2): 153-159. 
20. Vafaeimanesh, J., Bagherzadeh, M., Heidari, A., Motii, F. and Parham, M. (2014): Diabetic patients infected with helicobacter pylori have a higher Insulin Resistance Degree. Caspian Journal of Internal Medicine, 5(3): 137-142.

21. Vafaeimanesh, J., Bagherzadeh, M., Mirzaei, A., Parham, M., Norouzinia, M. and Vafaee, $R$. (2016): Effect of Helicobacter pylori on metabolic syndrome parameters in diabetic patients. Gastroenterology and Hepatology from Bed to Bench, 9(Suppl1): S36-S41.
22. Yang, W. and Xuan, C. (2016): Influence of Helicobacter pylori infection on metabolic syndrome in old chinese people. Gastroenterology Research and Practice, 6(2):67-89.

23. Zhou, X., Zhang, C., Wu, J. and Zhang, G. (2013): Association between Helicobacter pylori infection and diabetes mellitus: a meta-analysis of observational studies. Diabetes Research and Clinical Practice, 99(2): 200-208. 


\section{العلاقة بين عدوي البكتريا الحلزونية ومتلازمة اختلال الأيض الميض عند المصريين البالغين}

محمد يحيي محمد عوض الله، عبداللاه حسين الصادق، طارق مصطفي عمران،

\section{سعد الدين محمد الثريف}

قسمي الباطنة العامة والبالثولوجيا الاكلينيكية، كلية الطب جامعة الأزهر

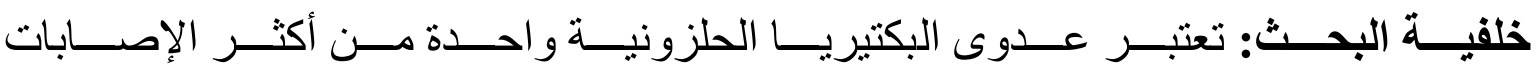

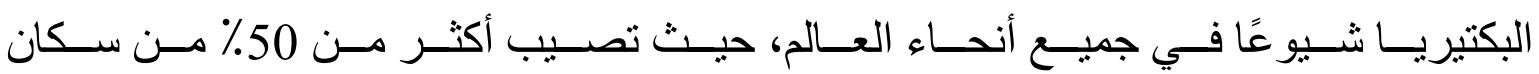

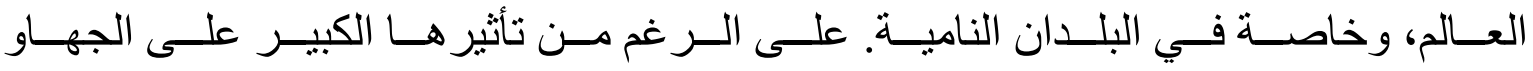

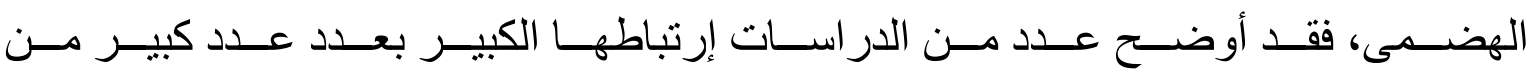
أمر اض القلب و الأوعية الدموية و إضطر ابات التمثيل الغذائى.

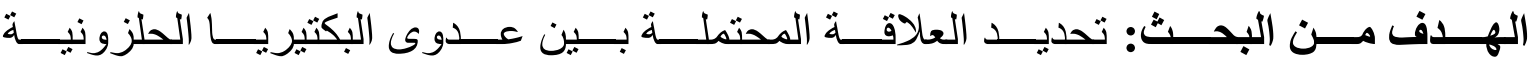

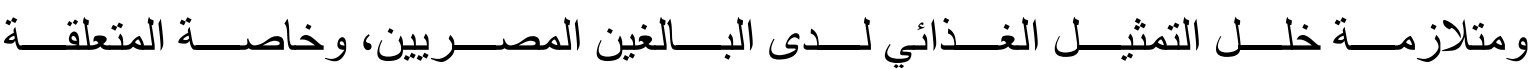

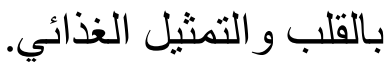

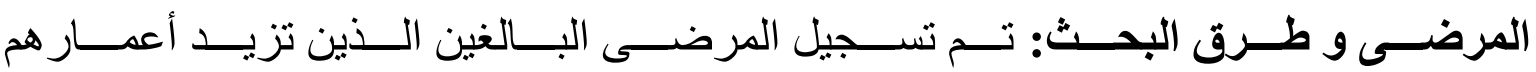

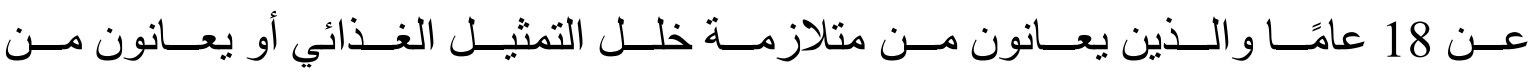

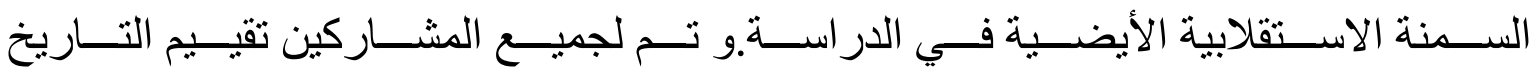
الدقيق و التقييم السريري.

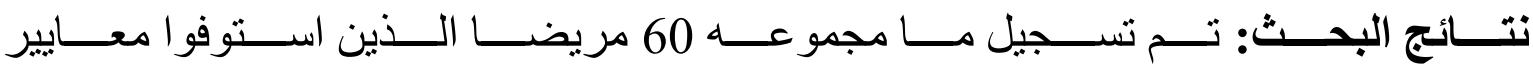

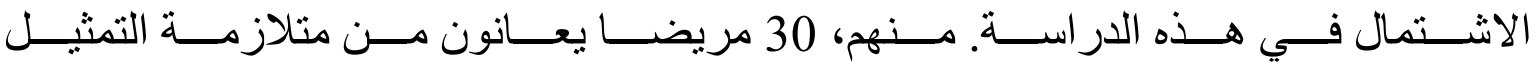

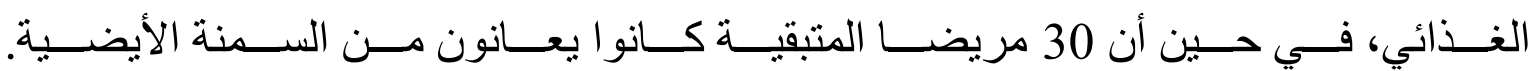

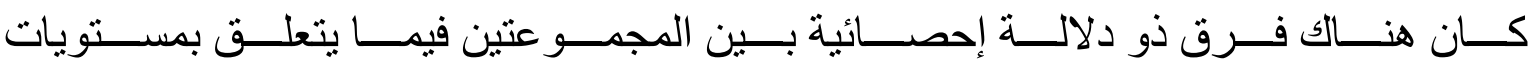

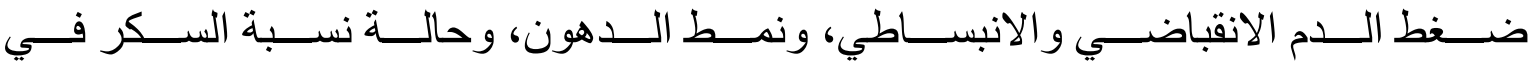

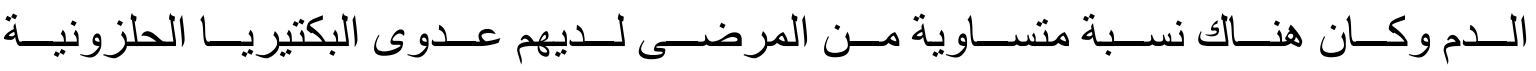

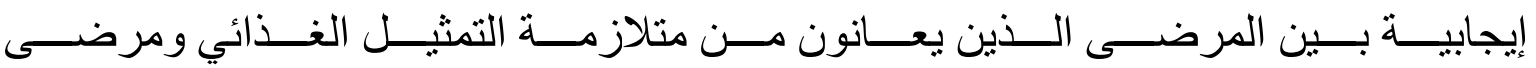




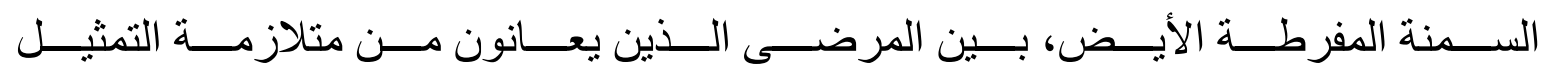

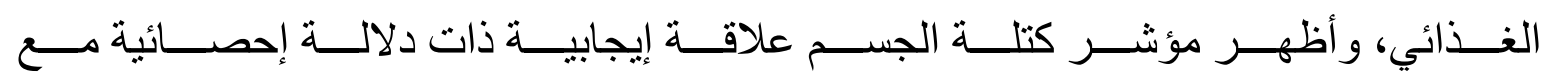
البكتيريا الحلزونية.

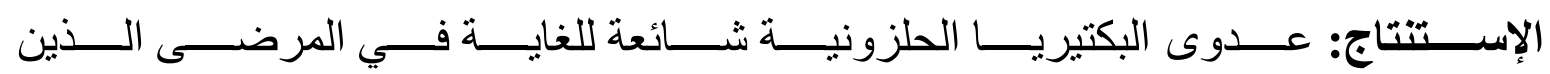

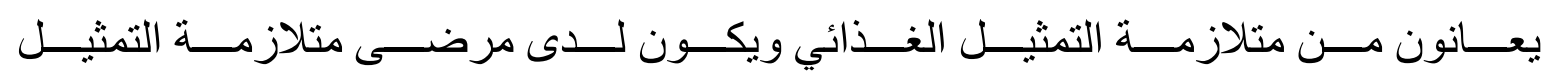

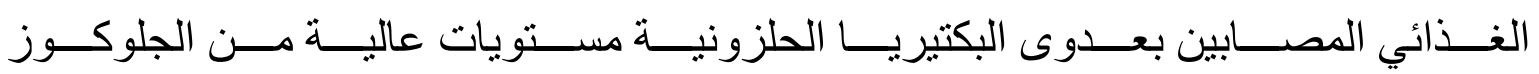

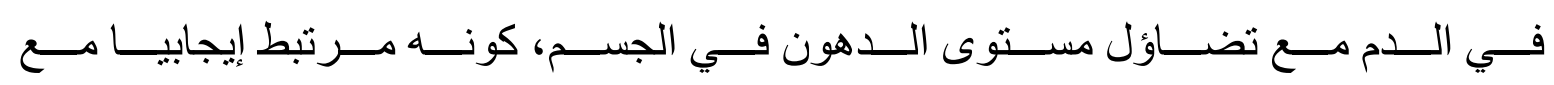

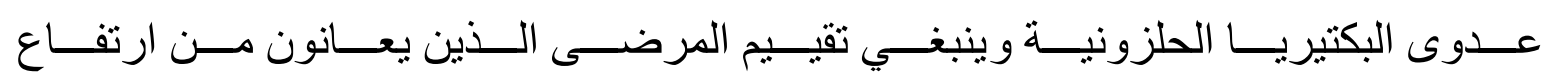
مؤشر كتلة الجسم معطليا لاستبعاد وجود عدوى البكتيريا الحلزونية. 